\title{
Increasing Tissue Oxygenation for Diabetic Wound Healing
}

\author{
Seung-Kyu Han \\ Department of Plastic Surgery, Korea University College of Medicine, Seoul, Korea
}

\begin{abstract}
Adequate tissue oxygenation is an essential factor during wound healing. Diabetic foot ulcers almost always accompany vascular insufficiency. Unfortunately, recovery of vascular insufficiency is difficult in diabetic patients because of both macro- and micro-circulations. This article presents the author's methods or innovations developed to increase tissue oxygenation for diabetic wound healing. Normobaric hyperoxic (NBO) therapy, which requires increasing the fractional inspired oxygen to almost $100 \%$ at normobaric pressure, is a potentially attractive alternative to hyperbaric oxygen therapy because of its high availability, good patient compliance, cost-effectiveness, decreased complications, and few technical requirements. NBO significantly increases tissue oxygenation level of diabetic feet. The foot lowering, rather than elevation, also significantly augments tissue oxygenation level of diabetic foot ulcers. Based on experience of the author's group, percutaneous transluminal angioplasty (PTA) is efficient enough to increase tissue oxygenation even in severely ischemic feet. The most severely ischemic group shows the most dramatic increase of tissue oxygenation after PTA. Monochromatic infrared energy, ultrasound, and pain scrambler therapy can also be used as adjunctive to improve tissue oxygen level in diabetic foot ulcers.
\end{abstract}

Keywords: Diabetic wound, Tissue oxygenation

\section{Introduction}

Many wound specialists dedicate themselves to conducting studies about diabetic wounds although there are various types of chronic wounds including pressure ulcers, lower leg ulcers (arterial or venous ulcer), and radiation ulcers. Why is understanding a diabetic wound important? It can be explained with two reasons. First, there are a great number of diabetic patients and the number is increasing even at present. According to the World Health Organization, approximately 5-10\% of adult patients are diabetic. Even in developed countries including the USA, where it has been known to have the most well managed diabetic patients, approximately 15$25 \%$ of diabetic patients develop diabetic foot (diabetic foot ulcers, diabetic wounds, or diabetic ulcers). Second, another reason that the diabetic wound has been of interest is that its pathophysiology, diagnosis, and treatment are not simple but rather complex because diabetic patients display a variety of diabetic complications. There is a complex pathophysiological connection between diabetes and wound healing impairment. Vascular, neurological, immunological and biochemical problems lead to the hindrance of tissue restoration.

Diabetic foot ulcers almost always accompany vascular insufficiency, polymicro-
Review Article

Received: January 26, 2017

Revised: May 6, 2017

Accepted: May 6, 2017

Corresponding author:

Seung-Kyu Han, M.D., Ph.D.

Department of Plastic Surgery, Korea

University Guro Hospital, 148 Gurodong-ro,

Guro-gu, Seoul 08308, Korea

Tel: +82-2-2626-3333

Fax +82-2-868-6698

E-mail: pshan@kumc.or.kr

No potential conflict of interest relevant to this article was reported.

This is an Open Access article distributed under the terms of the Creative Commons Attribution NonCommercial License (http://creativecommons.org/ licenses/by-nc/4.0/) which permits unrestricted noncommercial use, distribution, and reproduction in any medium, provided the original work is properly cited.

๑) 2017 The Korean Wound Management Society 
bial infection, and abnormal pressure distribution due to chronic neuropathy. Recovery of vascular insufficiency is difficult because of both macro- and micro-circulations. Adequate tissue oxygenation is an essential factor during diabetic wound healing. ${ }^{1,2}$ Increasing blood and tissue oxygen contents help maintain cellular integrity and function by acting as a substrate for ATP synthesis and a supply of metabolic energy. A recent study suggested that oxygen may support the differentiation of fibroblasts to myofibroblasts, which are responsible for wound contracture, by a variety of mechanisms. ${ }^{3}$ Increased wound oxygenation promotes the synthesis of collagen by fibroblasts, and its deposition provides tensile strength to the matrix for angiogenesis and tissue remodeling. ${ }^{4-6}$ Oxygen also reduces infection in chronic wounds because of an important mechanism by which polymorphonuclear leukocytes selectively kill bacteria that rely on oxygen. $5,7,8$

During the past 17 years, the author has been interested in the development of new techniques and materials that can improve diabetic wound healing through a procedure of the least degree of invasiveness. The purpose of this article is to present the author's methods or innovations developed to increase tissue oxygenation for diabetic wound healing. The author would like to emphasize that the common subjects which have already been well dealt with elsewhere are only briefly in this article. Only those subjects regarding the technologies specifically used in the author's Diabetic Wound Center have been highlighted.

\section{Measurement of Tissue Oxygenation}

Unlike non-diabetic patients, microcirculation in diabetic patients is commonly compromised, regardless of the status of the macrocirculation. ${ }^{9}$ Multiple factors contribute to the differences noted in macrocirculation patency and tissue oxygenation in diabetic patients. For example, while the skin-capillary density of diabetics is similar to that of non-diabetic persons, the basement membrane of capillary walls is thicker. ${ }^{10,11}$ This is attributable to high hydrostatic pressure of the lower extremities resulting in damage to capillary endothelial cells. This process ultimately leads to basement membrane thickening and arteriole hyalinosis, which in turn leads to problems in capillary autoregulation and impaired vasodilatory function. Another factor contributing to impaired microcirculation is an increase in non-enzymatic advanced glycosylation end products (AGE) associated with hyperglycemia. Serum, vessel wall, and extracellular matrix AGE levels are increased in persons with diabetes mellitus, and the accumulation of AGEs is hypothesized to contribute to microangiopathy with increased thickness and decreased permeability of capillary basement membranes, resulting in defects in vasodilatory function. ${ }^{12}$ Hematologic changes in red blood cells (RBCs) are also postulated to contribute to microangiopathy. Hyperglycemia leads to non-enzymatic glycosylation of spectrin on the surface of RBCs, resulting in increased hemoagglutination and stiffening of the cellular surface. ${ }^{13,14}$ When passing through vessels with small diameters (such as lower extremity capillaries), the normally flexible RBCs crumple into flatshaped structures. However, the increased stiffness of RBCs in persons with diabetes prevents this shape change, which inhibits RBC passage through capillaries or inflicts trauma on endothelial cells as the stiffer RBCs forcibly pass through lower extremity capillaries. Diabetic neuropathy can also contribute to decreased tissue oxygen perfusion by opening arteriovenous (AV) shunts between arterioles and venules. Normally, sympathetic nerves act to maintain the constrictive tone of these AV shunts, preserving capillary blood flow, but sympathetic denervation releases this tone, opening these shunts. ${ }^{14,15}$ These AV shunts then become circulatory bypasses, decreasing capillary blood flow.

Therefore, tissue oxygenation measurement is recommended when determining tissue viability and selecting amputation levels in patients with diabetic foot ulcers. The measurement of transcutaneous partial oxygen tension $\left(\mathrm{TcpO}_{2}\right)$ is a non-invasive, reproducible method which can detect if the peripheral arterial microcirculation is compromised. ${ }^{16-18}$ $\mathrm{TcpO}_{2}$, which represents actual tissue oxygen perfusion, is widely acknowledged to be a reliable method for evaluating macro- and micro-circulations in diabetic patients. ${ }^{19}$ The technique of $\mathrm{TcpO}_{2}$ measurement is dependent on oxygen diffusion across skin from dermal capillaries maximally dilated by heat. The diffused oxygen amount is dependent on capillary oxygen delivery as a function of arterial oxygen content and blood flow. ${ }^{16}$ Although opinions vary, minimal $\mathrm{TcpO}_{2}$ values thought to be required for adequate wound healing lie between 25 and $40 \mathrm{mmHg}$. ${ }^{18-21}$

\section{Normobaric Hyperoxic Therapy}

Improving tissue oxygenation with hyperbaric oxygen (HBO) therapy has been a reasonable therapeutic strategy with a relatively low risk of complications. ${ }^{22-24}$ Current literature sug- 
gests that HBO therapy is effective for increasing blood and tissue oxygenation in the management of diabetic foot ulcers. Increasing oxygen levels in hypoxic tissues may help maintain cellular function and integrity thereby contributing to wound healing. ${ }^{25-28}$ Therefore, HBO therapy is used as an adjunctive therapy to treat several clinical conditions associated with tissue hypoxia such as severe soft tissue infections and ischemic diabetic foot ulcers. ${ }^{29}$ However, clinical applications of $\mathrm{HBO}$ therapy are limited by high-cost, low availability of HBO chambers, need for trained personnel to monitor patients, poor patient compliance because of headache and otalgia, and the possibility of high oxidative potential contributing to pulmonary edema and brain injury. ${ }^{30}$ The occurrence of oxygen-toxic seizures after HBO therapy has also been reported. ${ }^{31}$ Cardiopulmonary, nephrologic, and neurologic comorbidities may be more frequent in patients with diabetic foot ulcers, who commonly have a poor general health condition. In addition, many patients with diabetic feet have difficulty moving to a HBO chamber or may have claustrophobia. For these reasons, the use of HBO therapy has been limited in patients with diabetic feet.

Normobaric hyperoxic (NBO) therapy, which requires increasing the fractional inspired oxygen to almost $100 \%$ at normobaric pressure, has gained great interest in the treatment of cerebral ischemia. ${ }^{32-35}$ Several animal and clinical studies on NBO therapy as adjuvant treatment to attenuate infarct volume after stroke and to improve functional outcomes after brain trauma have provided compelling evidence in past years. NBO therapy is a potentially attractive alternative to HBO therapy because of its high availability, good patient compliance, cost-effectiveness, decreased complications, and few technical requirements.

The author's group has performed a clinical study to evaluate the effect of NBO therapy on tissue oxygenation of diabetic feet since no reports regarding the effect of NBO therapy on its potential to contribute to wound healing had been published. ${ }^{36}$ The study included 100 patients with diabetic foot ulcers. $\mathrm{TcpO}_{2}$ values of diabetic feet were measured before, during, and after NBO therapy. The mean $\mathrm{TcpO}_{2}$ values before, during, and after therapy were $46.6 \pm 21.5,88.9 \pm$ 48.0, and $49.9 \pm 23.8 \mathrm{mmHg}(\mathrm{p}<0.001)$, respectively. The lower the initial $\mathrm{TcpO}_{2}$ level, the more $\mathrm{TcpO}_{2}$ increased. The results reveal that NBO therapy significantly increases tissue oxygenation level of diabetic feet.

Our patients with diabetic foot ulcers receives NBO therapy for 3-4 hours per day (1 hour per session and 3-4 sessions per day). Up to now, hundreds of patients have been treated with this protocol in our center, and no patients have experienced any complications associated with the NBO therapy such as headache or otalgia. Another great advantage of NBO therapy is that patients are much more cooperative compared to that of $\mathrm{HBO}$ therapy. As patients can watch the increase in $\mathrm{TcpO}_{2}$ on their feet when $\mathrm{TcpO}_{2}$ is measured before and during the NBO therapy, they realize that the NBO therapy is very effective for elevating tissue oxygenation of the wound bed, which helps with their compliance with the therapy.

\section{Foot Lowering}

In managing diabetic foot ulcers, foot elevation has been generally recommended to reduce edema and prevent other sequential problems. Elevation decreases the local hydrostatic pressure and the superficial venous pressure, thereby reducing edema and the interstitial spillage of macromolecules. By decreasing the extravasation of macromolecules into the extravascular space, the inflammatory response is reduced. Stifling of the inflammatory response may limit the release of mediators detrimental to the process of wound healing. ${ }^{3}$ However, foot elevation may decrease tissue oxygenation of the foot more than the dependent position since the dependent position is known to increase blood flow within the arterial system..$^{4 \cdot 6}$ In addition, diabetic foot ulcers, which have peripheral vascular insufficiency, generally have less edema than other wounds. Therefore, the author's group argued that foot elevation might not be helpful for healing of vascularlycompromised diabetic foot ulcers.

The author's group carried out a study to evaluate the influence of foot height on tissue oxygenation and to determine optimal foot position to accelerate wound healing of diabetic foot ulcers. ${ }^{37}$ The study included 122 cases of diabetic foot ulcer patients. $\mathrm{TcpO}_{2}$ values of diabetic feet were measured before and after foot elevation. Elevation was achieved by placing a foot over four cushions. We also measured foot $\mathrm{TcpO}_{2}$ values before and after lowering the feet. Feet were lowered to the patient's tibial height, approximately 30-35 $\mathrm{cm}$, beside a bed handrail. Foot elevation lowered $\mathrm{TcpO}_{2}$. Before elevation, the average $\mathrm{TcpO}_{2}$ was $32.5 \pm 22.2 \mathrm{mmHg}$, but the $\mathrm{TcpO}_{2}$ decreased to $23.8 \pm 23.1 \mathrm{mmHg}$ after elevation, representing a decrease of $26.8 \%$. In contrast, foot lowering had a positive effect on $\mathrm{TcpO}_{2}$. The average baseline $\mathrm{TcpO}_{2}$ was $44.6 \pm 23.8 \mathrm{mmHg}$ and increased to $58.0 \pm 25.9 \mathrm{mmHg}$ 
after lowering; an increase of $30.1 \%$. The lower the initial $\mathrm{TcpO}_{2}$ level, the more the $\mathrm{TcpO}_{2}$ level increased. The foot lowering, rather than elevation, significantly augments $\mathrm{TcpO}_{2}$ and may stimulate healing of diabetic foot ulcers.

In the author's center, we obtain $\mathrm{TcpO}_{2}$ measurements from all diabetic foot ulcer patients, and as became evident, if foot lowering is beneficial, we encourage the patients to lower their feet.

\section{Percutaneous Transluminal Angioplasty}

Bypass graft surgery and percutaneous transluminal angioplasty (PTA) are generally recommended to improve tissue oxygenation of the ischemic diabetic foot. Bypass graft surgery has been the mainstay of revascularization therapy for the ischemic foot. There are many reports showing thevalue of bypass surgery; however, the surgery is an invasive procedure associated with perioperative mortality and morbidity. ${ }^{32}$ In particular, patients with severe ischemia are at a higher risk of subsequent cardiovascular events, including myocardial infarction, stroke, and death. ${ }^{33,34}$ In addition, bypass surgery requires at least one patent artery and a good vein.

Alternatively, PTA has been used with increased frequency in recent years for treatment of the diabetic foot. ${ }^{35,36}$ PTA is a less invasive procedure than the bypass graft surgery and several studies have demonstrated good results for PTA in terms of patency and limb salvage. ${ }^{27-31}$ In PTA, there is no need for general anesthesia and there are less associated wound problems. PTA allows for preservation of the saphenous vein and thus can be performed repeatedly. Furthermore, based on improved technical options for PTA, a significantly better outcome than before is now expected for the procedure. However, there are still concerns about the feasibility and effectiveness of PTA in severely ischemic feet. Even though certain recent studies suggested that PTA might be as effective as bypass surgery ${ }^{26,28,32}$ their conclusions were only based on clinical symptoms rather than objective setting. Thus, bypass graft surgery is still preferred for severely ischemic diabetic foot patients. ${ }^{33-35}$

In experience of the author's group, PTA was efficient enough to increase tissue oxygenation even in severely ischemic feet. ${ }^{38}$ We have performed a study to objectively compare the outcomes of PTA according to the degree of ischemia in order to estimate the efficacy of PTA in severely ischemic diabetic feet. The results were that the most severely ischemic group had the most dramatic increase of tissue oxy- genation after PTA. As such, PTA can be an effective method for increasing tissue oxygenation even in the severely ischemic diabetic feet. These days we do not use bypass graft surgery any more, but do PTA to increase tissue oxygenation on the wound area.

\section{Adjunctive Therapy}

Monochromatic infrared energy (MIRE) involves the delivery of near-infrared energy at $890 \mathrm{~nm}$ wavelength to the skin. MIRE modality increases nitric oxide (NO) in the blood and plasmas. ${ }^{39} \mathrm{NO}$ is a potent endogenous vasodilator that can be liberated from tightly bound hemoglobin on exposure to various wave lengths of energy. NO is thought to be the molecule that accounts for the increased wound healing of oral supplementation with L-arginine or topical nitroglycerin. An elevation in NO has been suggested to be the basis of improved rates and quality of wound healing during L-arginine or nitroglycerin therapy since dietary L-arginine is a source of NO. NO is bound to the cysteine of the beta chain of hemoglobin during the passage of red blood cells through the lungs. In addition to oxygen, hemoglobin also transports NO throughout the body. NO is thought to aid in vascular perfusion by dilatation of arterioles, thus enhancing tissue oxygenation, nutrient delivery, removal of waste products of metabolism, and successful wound healing. NO also has a powerful anabolic effect that manifests itself as improved tissue remodeling. The MIRE device was first cleared by the FDA in 1994 for the purpose of enhancing circulation and reducing pain. The treatment using the MIRE device is recommended for 30 minutes each day .

Ultrasound is defined as a mechanical vibration above the upper threshold of human hearing $(>20 \mathrm{KHz}) .{ }^{39}$ Ultrasound therapy involves the application of high-frequency sound waves transmitted through water or gel to promote wound healing. Although the exact mechanism underlying its clinical effects is not known, therapeutic ultrasound has been shown to have a variety of effects at a cellular level including angiogenesis, leukocyte adhesion, growth factor and collagen production, and increases in macrophage responsiveness, fibrinolysis, and nitric oxide levels. There are two types of ultrasounds. High-frequency ( $\mathrm{MHz}$ range: $1-3 \mathrm{MHz}$ ) ultrasounds enhance three phases of wound healing by creating local thermal effects. They increase angiogenesis as well as wound contraction, collagen deposition, granulation tissue formation, and scar pliability. Low-frequency $(\mathrm{KHz})$ ultrasounds debride 
necrotic tissue, reduce wound bioburden, and enhance wound healing.

Pain scrambler therapy (or Calmare pain therapy) can also help increase blood flow. ${ }^{39}$ Many diabetic foot patients suffer from chronic pain on the lower extremity, some of which are very painful. These foot conditions should not be taken lightly. The condition results in vasoconstriction. Even though the pain is basically associated with peripheral neuropathy, successful pain management can enhance increase of blood flow.

\section{References}

1. Inlow S, Orsted H, Sibbald RG. Best practices for the prevention, diagnosis, and treatment of diabetic foot ulcers. Ostomy Wound Manage 2000;46:55-68.

2. Nylander G, Nordstrom H, Eriksson E. Effects of hyperbaric oxygen on oedema formation after a scald burn. Burns Incl Therm Inj 1984;10:193-6.

3. Roy S, Khanna S, Bickerstaff AA, et al. Oxygen sensing by primary cardiac fibroblasts: a key role of p21(Waf1/Cip1/ Sdi1). Circ Res 2003;92:264-71.

4. Barnikol WK, Potzschke H. A novel, non-invasive diagnostic clinical procedure for the determination of an oxygenation status of chronic lower leg ulcers using peri-ulceral transcutaneous oxygen partial pressure measurements: results of its application in chronic venous insufficiency (CVI). Ger Med Sci 2012;10:Doc11.

5. Gordillo GM, Sen CK. Revisiting the essential role of oxygen in wound healing. Am J Surg 2003;186:259-63.

6. Hunt TK, Pai MP. The effect of varying ambient oxygen tensions on wound metabolism and collagen synthesis. Surg Gynecol Obstet 1972;135:561-7.

7. Allen DB, Maguire JJ, Mahdavian M, et al. Wound hypoxia and acidosis limit neutrophil bacterial killing mechanisms. Arch Surg 1997;132:991-6.

8. Knighton DR, Halliday B, Hunt TK. Oxygen as an antibiotic. The effect of inspired oxygen on infection. Arch Surg 1984; 119:199-204.

9. Mayrovitz HN, Larson PB. Functional microcirculatory impairment: A possible source of deduced skin oxygen tension in human diabetes mellitus. Microvasc Res 1996;52:115-26.

10. Hile C, Veves A. Diabetic neuropathy and microcirculation. Curr Diab Rep 2003;3:446-51.

11. Hile C, Veves A. Microcirculation of the diabetic foot. In: Johnstone MT, Veves A., eds. Diabetes and cardiovascular disease, 2nd ed, Totowa: Humana Press Inc.; 2005:403-18.

12. Wautier JL, Guillausseau PJ. Advanced glycation end products, their receptors and diabetic angiopathy. Diabetes
Metab 2001;27:535-42.

13. Morain WD, Colen LB. Wound healing in diabetes mellitus. Clin Plast Surg 1993;17:493-501.

14. Park DJ, Kim HS, Han SK, et al. Comparison of doppler and CT angiography as a predictor of healing diabetic foot ulcers. J Korean Soc Plast Reconstr Surg 2008;35:495-500.

15. Vinik Al, Erbas T, Park TS, et al. Methods for evaluation of peripheral neurovascular dysfunction. Diabetes Technol Ther 2001;3:29-50.

16. Byrne P, Provan JL, Ameli FM, et al. The use of transcutaneous oxygen tension, measurements in the diagnosis of peripheral vascular insufficiency. Ann Surg 1984;200:159-65.

17. Cina C, Katsamouris A, Megerman J, et al. Utility of transcutaneous oxygen tension measurements in peripheral arterial occlusive disease. J Vasc Surg 1984;1:362-71.

18. Colen LB, Uroskie T. Foot reconstruction. In: Mathes SJ, ed. Plastic Surgery. Vol. 6. Philadelphia: Saunders Elsevier; 2006; 1403-54.

19. Ballard JL, Eke CC, Bunt TJ, et al. A prospective evaluation of transcutaneous oxygen measurements in the management of diabetic foot problems. J Vasc Surg 1995;22:48590.

20. Misuri A, Lucertini G, Nanni A, et al. Predictive value of transcutaneous oximetry for selection of the amputation level. J Cardiovasc Surg 2000;41:83-7.

21. Bunt TJ, Holloway GA. TcPO2 as an accurate predictor of therapy in limb salvage. Ann Vasc Surg 1996;10:224-27.

22. Pomposelli FB, Kansal N, Hamdan AD, et al. A decade of experience with dorsalis pedis artery bypass: analysis of outcome in more than 1000 cases. Journal of Vascular Surgery 2003;37:307-15.

23. Malyar N, Furstenberg T, Wellmann J, et al. Recent trends in morbidity and in-hospital outcomes of in-patients with peripheral arterial disease: a nationwide population-based analysis. European Heart Journal 2013;34:2706-14.

24. Hirsch AT, Duval S. The global pandemic of peripheral artery disease. Lancet (London, England) 2013;382:1312-4.

25. Fossaceca R, Guzzardi G, Cerini P, et al. Endovascular treatment of diabetic foot in a selected population of patients with below-the-knee disease: is the angiosome model effective? Cardiovascular and Interventional Radiology 2013;36:63744.

26. Soderstrom MI, Arvela EM, Korhonen M, et al. Infrapopliteal percutaneous transluminal angioplasty versus bypass surgery as first-line strategies in critical leg ischemia: a propensity score analysis. Annals of Surgery 2010;252:765-73.

27. Dosluoglu HH, Cherr GS, Lall P, et al. Peroneal artery-only runoff following endovascular revascularizations is effective for limb salvage in patients with tissue loss. Journal of Vascular Surgery 2008;48:137-43.

28. Faglia E, Dalla Paola L, Clerici G, et al. Peripheral angioplasty 
as the first-choice revascularization procedure in diabetic patients with critical limb ischemia: prospective study of 993 consecutive patients hospitalized and followed between 1999 and 2003. European journal of vascular and endovascular surgery : the official journal of the European Society for Vascular Surgery 2005;29:620-7.

29. Graziani L, Piaggesi A. Indications and clinical outcomes for below knee endovascular therapy: review article. Catheterization and cardiovascular interventions: official journal of the Society for Cardiac Angiography \& Interventions 2010;75: 433-43.

30. Met R, Van Lienden KP, Koelemay MJ, et al. Subintimal angioplasty for peripheral arterial occlusive disease: a systematic review. Cardiovascular and Interventional Radiology 2008; 31:687-97.

31. Sigala F, Menenakos C, Sigalas P, et al. Transluminal angioplasty of isolated crural arterial lesions in diabetics with critical limb ischemia. VASA. Zeitschrift fur Gefasskrankheiten 2005;34:186-91.

32. lida O, Soga Y, Yamauchi Y, et al. Clinical efficacy of endovascular therapy for patients with critical limb ischemia attributable to pure isolated infrapopliteal lesions. Journal of Vascular Surgery 2013;57:974-81. e971.
33. Korhonen M, Biancari F, Soderstrom M, et al. Femoropopliteal balloon angioplasty vs. bypass surgery for CLI: a propensity score analysis. European journal of vascular and endovascular surgery: the official journal of the European Society for Vascular Surgery 2011;41:378-84.

34. Abu Dabrh AM, Steffen MW, Asi N, et al. Bypass surgery versus endovascular interventions in severe or critical limb ischemia. Journal of Vascular Surgery 2016;63:244-53. e211.

35. Sachs T, Pomposelli F, Hamdan A, et al. Trends in the national outcomes and costs for claudication and limb threatening ischemia: angioplasty vs bypass graft. Journal of Vascular Surgery 2011;54:1021-31. e1021.

36. Moon KC, Han SK, Lee YN, et al. Effect of normobaric hyperoxic therapy on tissue oxygenation in diabetic feet: a pilot study. J Plast Reconstr Aesthet Surg 2014;67:1580-6.

38. Kim HR, Han SK, Rha SW, et al. Effect of percutaneous transluminal angioplasty on tissue oxygenation in ischemic diabetic feet. Wound Repair Regen 2011;19-24.

37. Park DJ, Han SK, Kim WK. Is the foot elevation the optimal position for wound healing of a diabetic foot? J Plast Reconstr Aesthet Surg 2010;63:561-4.

39. Han SK. Innovations and Advances in Wound Healing (2nd Ed). Springer. 2015. 